\title{
Workability Behaviour of Powder Metallurgy Aluminium Composites
}

\author{
S. Narayan and A. Rajeshkannan \\ School of Engineering and Physics, Faculty of Science, Technology and Environment, The University of the South Pacific, \\ Laucala Campus, Private Mail Bag, Suva, Fiji
}

Correspondence should be addressed to S. Narayan; narayan_su@usp.ac.fj

Received 23 April 2014; Accepted 17 June 2014; Published 1 July 2014

Academic Editor: Thierry Barriere

Copyright (C) 2014 S. Narayan and A. Rajeshkannan. This is an open access article distributed under the Creative Commons Attribution License, which permits unrestricted use, distribution, and reproduction in any medium, provided the original work is properly cited.

An efficient way to find the workability limit for powder metallurgy parts has been suggested. Compacts of $\mathrm{Al}-4 \% \mathrm{TiC}, \mathrm{Al}-4 \% \mathrm{WC}$, $\mathrm{Al}-4 \% \mathrm{Fe}_{3} \mathrm{C}$, and $\mathrm{Al}-4 \% \mathrm{Mo}_{2} \mathrm{C}$ were produced to the relative density of 0.82 and 0.86 with three different geometries through primary operations of powder metallurgy routes. Each sintered compact was hot deformed to various strain levels till a visible crack appeared at the free surface. Oyane's fracture principle was used to develop a theory to study powder metallurgy compacts. A least square technique was used to determine the constants in fracture criteria and these equations were finally used to find workability limit. It is found that the projected technique was well in agreement with the experimental values.

\section{Introduction}

Powder metallurgy manufacturing technique is used to produce parts to close tolerance, intricate shapes, and near net shapes. It has proved to be cost effective of producing many parts such as porous materials, composite materials, refractory materials, and special high duty alloys [1-3] to be used in aircraft, automotive, and manufacturing industry. Further, powder metallurgy route is green manufacturing and energy efficient manufacturing compared to casting operation [4]. Aluminum metal matrix is used for wide range of industrial applications due to its exceptional properties such as low specific density, great strength, low thermal growth, and decent wear resistance and is cost-effective [59]. Ductile aluminum matrix strengthened with tougher and stiffer carbides offers a blend of properties of the metallic material and ceramic strengthening parts [10]. Titanium carbide and tungsten carbide based parts are presently used in high strength application where better strength, wear resistance, and corrosion resistance are necessary [11, 12] and aluminium reinforced with tungsten carbide prepared by warm accumulative roll bonding method exhibited enhanced mechanical properties [13]. The workability of the powder metallurgy parts plays an important part in defining if the powder metallurgy part will be shaped successfully or fracture initiates in the forming practice.

Workability is the amount of deformation in which a material can sustain the induced internal stresses of forming prior to failure. Workability features are dependent not only on the material but also on numerous forming parameters such as stress and strain rate, porosity, friction, and temperature $[14,15]$. Over the years, numerous models [1618] were established to study workability of conventional parts; however, they cannot be directly applied to powder metallurgy parts as the conventional parts are expected to follow volume constancy $[14,19,20]$, whereas powder metallurgy parts are expected to follow mass constancy [15, $21,22]$. These essential assumptions were used to develop the plasticity model for respective parts. Overall, the fracture mechanisms stated by numerous investigators $[23,24]$ depend highly on the extent of triaxiality and the equivalent strain and the stress triaxiality that rules the crack creation. In the case of powder metallurgy metal forming practice, the strain to fracture mainly depends on the formability stress factor and the strain path [15]. Abdel-Rahman and El-Sheikh [15] suggested the stress formability criteria $(\beta)$ 
for relating the effect of mean stress and the effective stress by employing theories projected by Kuhn and Downey [25] and Hwang and Kobayashi [26] for powder metallurgy parts. Numerous researches are established using Oyane's fracture principle to frame the mathematical model and matched with experimental outcomes showing good agreement [17, 27, 28]. Oyane's fracture principle states formality stress factor and the strain that has been effectively combined to create the workability limits for wrought parts [16, 17]. It is presented [16-18] that the idea of workability limit can be useful to account for the effect of formability stress factor and define the strain to fracture at any material point where the formability stress factor is constant throughout the process. For powder metallurgy parts this condition is not fulfilled $[14,15,29]$ and as projected in $[16,17]$, a workability limit should be supplemented with a fracture criterion to take into account the path dependence of fracture. The fracture criterion used in the workability limit (characterized by effective strain against formability stress factor at fracture) can be expressed by integrating formability stress factor over the strain path instead of experimental values. The current study is intended to develop a mathematical model using Oyane's fracture principle with certain alterations so as to suit for powder metallurgy parts. Additionally, a statistical technique is applied to explore the value for the constants obtained in the mathematical model, which is finally used for making workability limit plot to disclose the characteristics nature of sintered $\mathrm{Al}-4 \% \mathrm{TiC}, \mathrm{Al}-4 \% \mathrm{WC}, \mathrm{Al}-4 \% \mathrm{Fe}_{3} \mathrm{C}$, and $\mathrm{Al}-$ $4 \% \mathrm{Mo}_{2} \mathrm{C}$ compacts under hot upsetting.

\section{Experimental Details}

2.1. Materials and Characteristics. Aluminium powder of less than or equal to $150 \mu \mathrm{m}$ in size (diameter) and corresponding carbide powders, namely, titanium carbide, tungsten carbide, molybdenum carbide, and iron carbide, of less than or equal to $50 \mu \mathrm{m}$ in size (diameter) were used in this research. The sieve analysis and basic characterization of aluminium powder and the respective composition have been carried out using standard methods of testing and are given in Tables 1 and 2 , respectively.

2.2. Powder Blending and Compaction. The required quantity of aluminium and corresponding carbide powders were accurately weighed and mixed to obtain $\mathrm{Al}-4 \% \mathrm{TiC}, \mathrm{Al}-4 \% \mathrm{WC}$, $\mathrm{Al}-4 \% \mathrm{Fe}_{3} \mathrm{C}$, and $\mathrm{Al}-4 \% \mathrm{Mo}_{2} \mathrm{C}$ in a ball mill machine with powder mixed to stainless steel balls $(10 \mathrm{~mm}$ inn diameter) with a ratio of $1: 1$ by weight. Air tight containers were used here to prevent oxidation of aluminium powders. Towards the end of blending procedure a steady apparent density confirmed homogeneous mixture. The mixed powders were then compressed using 100 tons capacity hydraulic press into cylindrical billets of aspect ratio (height-to-diameter ratio) of $0.2,0.4$, and 0.6 . The corresponding compressing stresses were obtained from the compressibility curve prepared for each material so as to obtain an initial theoretical density of $0.82 \pm 0.01$ and $0.86 \pm 0.01$. Initial theoretical density is initial
TABLE 1: Sieve size analysis of aluminium powder.

\begin{tabular}{lccccccc}
\hline $\begin{array}{l}\text { Sieve size }(\mu \mathrm{m}) \\
\begin{array}{l}\text { Retention in } \\
\text { sieve (Weight \%) }\end{array}\end{array}$ & 0.2 & 0.3 & 16.3 & 55.3 & 9.5 & 7.9 & 10.5 \\
\hline
\end{tabular}

density of the preform divided by $100 \%$ density of the preform (no pores).

2.3. Ceramic Coating, Drying, and Sintering. Directly after compaction an indigenously developed ceramic coating was applied on the preforms. The ceramic coating was prepared by mixing alumina powder in acetone. This covering was allowed to dry for a period of 12 hours and then recoating was employed to the preforms in the direction of $90^{\circ}$ to that of the previous covering. Once more the preforms were allowed to dry for a period of 12 hours. The covering was applied to prevent oxidation of preforms during the sintering process. The ceramic coated preforms were dried in an electric muffle furnace at a temperature of $220^{\circ} \mathrm{C}$ for 30 minutes and then sintered at the temperature of $594^{\circ} \mathrm{C}$ for further 60 minutes.

2.4. Hot Deformation and Measurements. Eight specimens of each material and aspect ratio were prepared and sintered. Hot upsetting of the seven sintered preforms followed directly after the sintering process at a temperature of $594^{\circ} \mathrm{C}$ to the different levels of height strain. All seven deformed specimens and one undeformed specimen were left in the open air for atmospheric cooling. It was ensured that one of the specimens had visible crack on the bulging surface while others were prevented from this defect. The specimens were placed between two flat dies and the impact load (varying to achieve different height strains) was provided by the dropping hammer. The deformation was achieved in one blow of the hammer. The hot upsetting was carried out with no lubricant. Dimensional measurements such as deformed height $\left(h_{f}\right)$, deformed diameters, namely, contact diameter at the top surface $\left(D_{c 1}\right)$, contact diameter at the bottom surface $\left(D_{c 2}\right)$, and bulged diameter $\left(D_{b}\right)$, were carried out after every upsetting. The density measurements of the forged samples were carried out using Archimedes principle.

\section{Theoretical Analysis}

The formability stress index $(\beta)$ is used to describe the effect of hydrostatic stress $\left(\sigma_{m}\right)$ and the effective stress $\left(\sigma_{\text {eff }}\right)$ on the forming limit of powder metallurgy materials during upset forging. The formability stress index can be expressed as [15]

$$
\beta=\frac{3 \sigma_{m}}{\sigma_{\mathrm{eff}}}
$$

The effective or equivalent stress for powder metallurgy materials can be determined by using the appropriate yield criterion which should take the pore effect into account. A typical theorem is that the plastic deformation occurs when 
TABLE 2: Characterization of aluminium powder and its blends.

\begin{tabular}{|c|c|c|c|c|c|}
\hline Property & $\mathrm{Al}$ & $\mathrm{Al}-4 \% \mathrm{WC}$ & $\mathrm{Al}-4 \% \mathrm{TiC}$ & $\mathrm{Al}-4 \% \mathrm{Fe}_{3} \mathrm{C}$ & $\mathrm{Al}-4 \% \mathrm{Mo}_{2} \mathrm{C}$ \\
\hline Apparent density (g/cc) & 1.091 & 1.345 & 1.186 & 1.308 & 1.325 \\
\hline Flow rate, $(\mathrm{s} / 50 \mathrm{~g})$ by Hall Flow Meter & 87.306 & 79.647 & 85.202 & 80.559 & 80.481 \\
\hline Compressibility $(\mathrm{g} / \mathrm{cc})$ at pressure of $130 \pm 10 \mathrm{MPa}$ & 2.356 & 2.113 & 2.280 & 2.235 & 2.210 \\
\hline
\end{tabular}

the elasticity strain energy reaches a critical value [30-32]. The formulation can be written as

$$
A J_{2}^{\prime}+B J_{1}^{2}=Y^{2}=\delta Y_{0}^{2}
$$

where $A, B$, and $\delta$ are yield criterion parameters, $J_{1}$ and $J_{2}^{\prime}$ are the first invariant and second invariant of the stress tensor and stress deviator, respectively, $Y_{0}$ is the yield strength of a fully dense compact, and $Y$ is the yield strength of a partially dense material having relative density $R$. The parameters $J_{1}$ and $J_{2}^{\prime}$ in the cylindrical coordinate system can be written as

$$
\begin{aligned}
& J_{2}^{\prime}=\frac{1}{6}\left[\left(\sigma_{r}-\sigma_{\theta}\right)^{2}+\left(\sigma_{\theta}-\sigma_{z}\right)^{2}+\left(\sigma_{z}-\sigma_{r}\right)^{2}\right], \\
& J_{1}=\sigma_{r}+\sigma_{\theta}+\sigma_{z} .
\end{aligned}
$$

Here, for axisymmetric forging, $\sigma_{r}=\sigma_{\theta}, J_{2}^{\prime}$ and $J_{1}^{2}$ can be written as

$$
\begin{aligned}
& J_{2}^{\prime}=\frac{1}{6}\left(2 \sigma_{\theta}^{2}+2 \sigma_{z}^{2}-4 \sigma_{\theta} \sigma_{z}\right), \\
& J_{1}^{2}=4 \sigma_{\theta}^{2}+\sigma_{z}^{2}+4 \sigma_{\theta} \sigma_{z} .
\end{aligned}
$$

Substituting (4) into (2) gives

$$
\frac{A}{6}\left(2 \sigma_{\theta}^{2}+2 \sigma_{z}^{2}-4 \sigma_{\theta} \sigma_{z}\right)+B\left(4 \sigma_{\theta}^{2}+\sigma_{z}^{2}+4 \sigma_{\theta} \sigma_{z}\right)=\delta Y_{0}^{2} .
$$

As explained in $[33,34]$, the following yield criteria parameters are chosen in this research as $A=2+R^{2}, B=\left(1-R^{2}\right) / 3$, and $\delta=2 R^{2}-1$. Equation (5) can now be written as

$$
Y_{0}=\sigma_{\mathrm{eff}}=\left[\frac{\left(\sigma_{z}^{2}+2 \sigma_{\theta}^{2}-R^{2}\left(\sigma_{\theta}^{2}+2 \sigma_{\theta} \sigma_{z}\right)\right)}{2 R^{2}-1}\right]^{0.5} .
$$

Dividing (6) by axial stress, $\sigma_{z}$ gives the expression for effective stress ratio in terms of cylindrical coordinates as

$$
\frac{\sigma_{\mathrm{eff}}}{\sigma_{z}}=\left[\frac{1+2\left(\sigma_{\theta} / \sigma_{z}\right)^{2}-R^{2}\left(2\left(\frac{\sigma_{\theta}}{\sigma_{z}}\right)+\left(\sigma_{\theta} / \sigma_{z}\right)^{2}\right)}{2 R^{2}-1}\right]^{0.5}
$$

According to Narayanasamy et al. $[35,36]$, the strain increment ratio $\left(d \varepsilon_{\theta} / d \varepsilon_{z}\right)$ in a triaxial stress state is given by

$$
\frac{d \varepsilon_{\theta}}{d \varepsilon_{z}}=\frac{\left(2+R^{2}\right) \sigma_{\theta}-R^{2}\left(\sigma_{z}+2 \sigma_{\theta}\right)}{\left(2+R^{2}\right) \sigma_{z}-R^{2}\left(\sigma_{z}+2 \sigma_{\theta}\right)} .
$$

The hoop stress $\left(\sigma_{\theta}\right)$ under triaxial stress state condition can be determined from (8) as given below:

$$
\begin{array}{r}
\frac{d \varepsilon_{\theta}}{d \varepsilon_{z}}\left[\left(2+R^{2}\right) \sigma_{z}-R^{2}\left(\sigma_{z}+2 \sigma_{\theta}\right)\right] \\
=\left(2+R^{2}\right) \sigma_{\theta}-R^{2}\left(\sigma_{z}+2 \sigma_{\theta}\right) \\
\sigma_{\theta}=\left[\frac{2\left(d \varepsilon_{\theta} / d \varepsilon_{z}\right)+R^{2}}{2-R^{2}+2 R^{2}\left(d \varepsilon_{\theta} / d \varepsilon_{z}\right)}\right] \sigma_{z} .
\end{array}
$$

Further, rearranging (9)

$$
\frac{\sigma_{\theta}}{\sigma_{z}}=\left[\frac{2\left(d \varepsilon_{\theta} / d \varepsilon_{z}\right)+R^{2}}{2-R^{2}+2 R^{2}\left(d \varepsilon_{\theta} / d \varepsilon_{z}\right)}\right] .
$$

Under triaxial stress state cylindrical coordinates, the hydrostatic stress can be written as follows: assuming $\sigma_{\theta}=\sigma_{r}$,

$$
\sigma_{m}=\frac{\sigma_{r}+\sigma_{\theta}+\sigma_{z}}{3}=\frac{2 \sigma_{\theta}+\sigma_{z}}{3} .
$$

Further, rearranging (11)

$$
\frac{\sigma_{m}}{\sigma_{z}}=\frac{1}{3}\left(1+\frac{2 \sigma_{\theta}}{\sigma_{z}}\right) .
$$

The formability stress index under triaxial stress state condition (1) can be written as

$$
\beta=3\left[\frac{\left(\sigma_{m} / \sigma_{z}\right)}{\left(\sigma_{\mathrm{eff}} / \sigma_{z}\right)}\right] .
$$

Shima and Oyane [37] proposed a fracture model as

$$
\int_{0}^{\varepsilon_{\mathrm{eff}}^{f}}\left(1+\left(\frac{\sigma_{m}}{C_{1} \sigma_{\mathrm{eff}}}\right)\right) d \varepsilon_{\mathrm{eff}}=C_{2}
$$

where $C_{1}$ and $C_{2}$ are material constants.

Using (1), Oyane's fracture model can now be written as

$$
\int_{0}^{\varepsilon_{\mathrm{eff}}^{f}}\left(1+\left(\frac{\beta}{3 C_{1}}\right)\right) d \varepsilon_{\mathrm{eff}}=C_{2} .
$$

The formability stress index at fracture is constant and (15) can be transformed to

$$
\varepsilon_{\mathrm{eff}}^{f}=\frac{3 C_{1} C_{2}}{\left(3 C_{1}+\beta^{f}\right)},
$$

where $\beta^{f}$ is the value of $\beta$ at fracture and $\varepsilon_{\text {eff }}^{f}$ is the effective strain at fracture. Equation (16) obtained from Oyane's fracture criterion involving two constants, $C_{1}$ and $C_{2}$, describes 


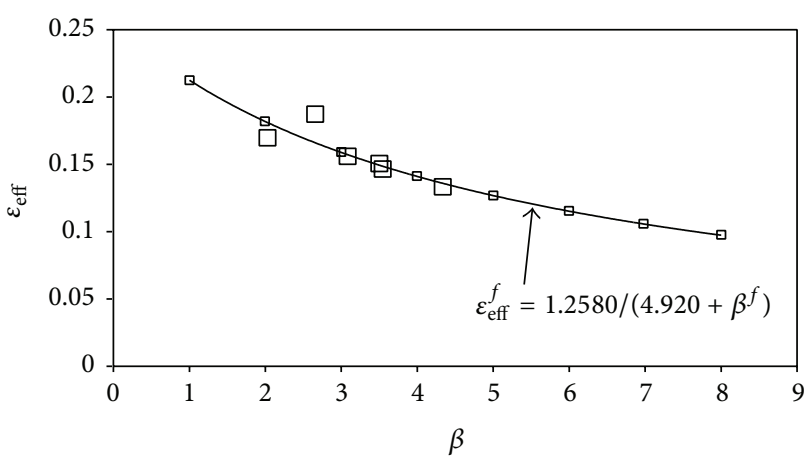

$\square \mathrm{TiC}$

Figure 1: Workability limit for Al-4\%TiC.

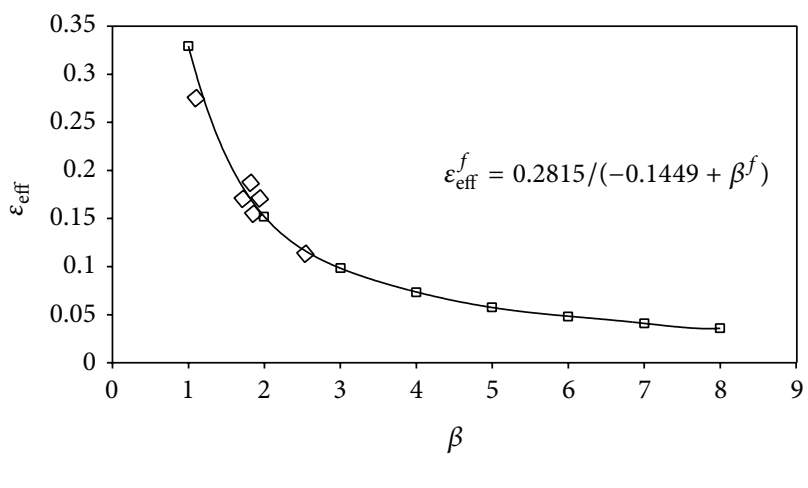

$\diamond \mathrm{WC}$

Figure 2: Workability limit for Al-4\%WC.

the workability limit in the form of a hyperbola. The effective strain $\left(\varepsilon_{\text {eff }}\right)$ in terms of cylindrical coordinates as explained elsewhere $[36,38]$ under triaxial stress state condition is expressed as

$$
\begin{aligned}
\varepsilon_{\mathrm{eff}}= & {\left[\left(\frac{2}{(3(2+R))}\right)\left[\left(\varepsilon_{z}-\varepsilon_{\theta}\right)^{2}+\left(\varepsilon_{\theta}-\varepsilon_{z}\right)^{2}\right]\right.} \\
& \left.+\left(\frac{\left(\varepsilon_{z}+2 \varepsilon_{\theta}\right)^{2}}{3}\right)\left(1-R^{2}\right)\right]^{0.5}
\end{aligned}
$$

where $\varepsilon_{\theta}$ is the true hoop strain and $\varepsilon_{z}$ is the true axial strain.

\section{Results and Discussion}

The upsetting tests on $\mathrm{Al}-4 \% \mathrm{TiC}, \mathrm{Al}-4 \% \mathrm{WC}, \mathrm{Al}-4 \% \mathrm{Fe}_{3} \mathrm{C}$, and $\mathrm{Al}-4 \% \mathrm{Mo}_{2} \mathrm{C}$ cylindrical powder metallurgy preforms were carried out. For each composition, three different aspect ratios (height to diameter ratio) with two different percentage theoretical densities were prepared and hot deformed without any lubricant, thus providing six different sets of experimental data for each composition. Aspect ratios of 0.2 , 0.4 , and 0.6 and initial theoretical density of $82 \%$ and $86 \%$ were used in this experiment. The initial height, diameter, and preform density were measured and the same was measured

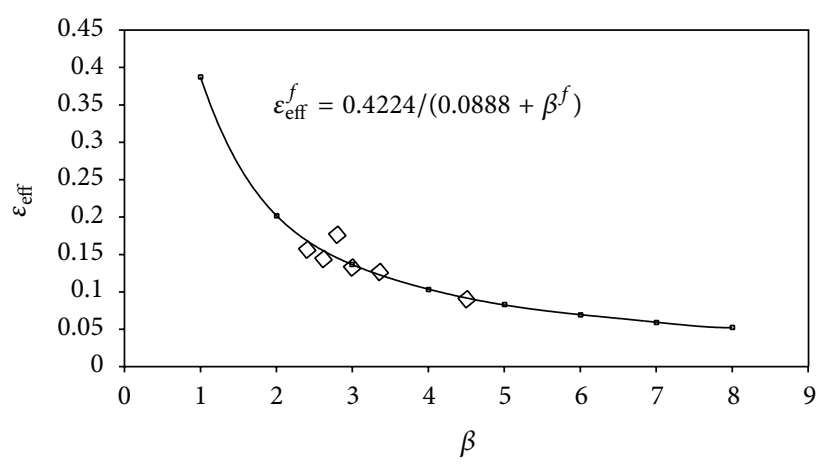

$\diamond \mathrm{Fe}_{3} \mathrm{C}$

Figure 3: Workability limit for $\mathrm{Al}-4 \% \mathrm{Fe}_{3} \mathrm{C}$.

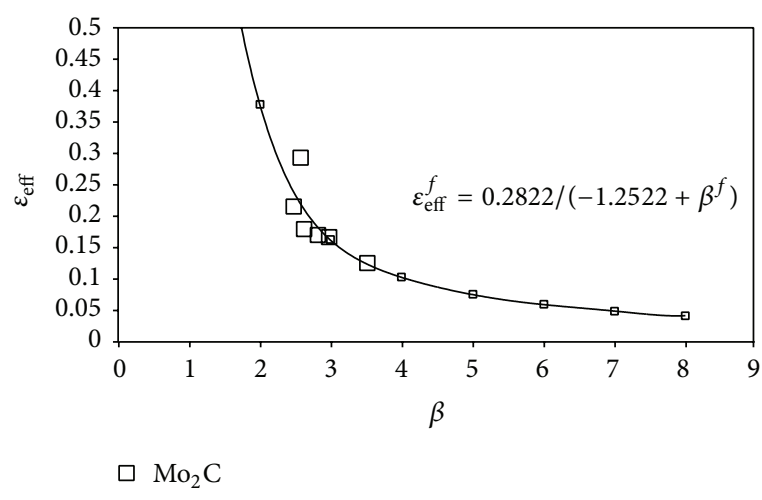

Figure 4: Workability limit for $\mathrm{Al}-4 \% \mathrm{Mo}_{2} \mathrm{C}$.

including the bulged diameter for different strain levels until preform fracture. From the measured parameters the effective strain $\left(\varepsilon_{\text {eff }}^{f}\right)$ and stress formability factor $\left(\beta^{f}\right)$ at fracture were determined for $\mathrm{Al}-4 \% \mathrm{TiC}, \mathrm{Al}-4 \% \mathrm{WC}, \mathrm{Al}-4 \% \mathrm{Fe}_{3} \mathrm{C}$, and $\mathrm{Al}-$ $4 \% \mathrm{Mo}_{2} \mathrm{C}$ as shown in Table 3 .

It can be seen from Table 3 that $\varepsilon_{\text {eff }}^{f}$ rises and $\beta^{f}$ decreases with increasing aspect ratio regardless of initial relative density and compositions. Additionally, $\varepsilon_{\text {eff }}^{f}$ is found to be higher for lower initial relative density compacts in comparison to higher relative density compacts. In general, $\varepsilon_{\text {eff }}^{f}$ was found to be higher in WC reinforced aluminium matrix and lowest in $\mathrm{Fe}_{3} \mathrm{C}$ strengthen aluminium matrix. Furthermore, $\beta^{f}$ is found to be higher for higher initial relative density compacts in comparison to lower relative density compacts. In general, $\beta^{f}$ was found to be lowest in WC reinforced aluminium matrix and highest in $\mathrm{TiC}$ strengthen aluminium matrix.

Using the least square method and the experimental data $\left(\varepsilon_{\text {eff }}^{f}\right.$ and $\left.\beta^{f}\right)$ obtained for Al-4\%TiC, Al-4\%WC, Al$4 \% \mathrm{Fe}_{3} \mathrm{C}$, and $\mathrm{Al}-4 \% \mathrm{Mo}_{2} \mathrm{C}$, the constants, $C_{1}$ and $C_{2}$, in the approximation to the workability limit equation (16) were determined and presented in Table 4 together with the approximation equations.

Figures 1,2,3, and 4 show the experimental data plotted with the approximation equation given in Table 4 for the respective compositions, $\varepsilon_{\text {eff }}^{f}$ against $\beta^{f}$. The experimental 
TABLE 3: Effective strain and stress formability factor at fracture.

\begin{tabular}{|c|c|c|c|c|}
\hline Composition & Relative density & Aspect ratio & $\varepsilon_{\mathrm{eff}}^{f}$ & $\beta^{f}$ \\
\hline \multirow{6}{*}{$\mathrm{Al}-4 \% \mathrm{TiC}$} & \multirow{3}{*}{0.82} & 0.2 & 0.1506 & 3.4845 \\
\hline & & 0.4 & 0.1820 & 2.8096 \\
\hline & & 0.6 & 0.1698 & 2.0257 \\
\hline & \multirow{3}{*}{0.86} & 0.2 & 0.1335 & 4.3333 \\
\hline & & 0.4 & 0.1462 & 3.5322 \\
\hline & & 0.6 & 0.1559 & 3.0762 \\
\hline \multirow{6}{*}{$\mathrm{Al}-4 \% \mathrm{WC}$} & \multirow{3}{*}{0.82} & 0.2 & 0.1557 & 1.8606 \\
\hline & & 0.4 & 0.1882 & 1.8209 \\
\hline & & 0.6 & 0.1705 & 1.7242 \\
\hline & \multirow{3}{*}{0.86} & 0.2 & 0.1132 & 2.5488 \\
\hline & & 0.4 & 0.1709 & 1.9264 \\
\hline & & 0.6 & 0.2753 & 1.1064 \\
\hline \multirow{6}{*}{$\mathrm{Al}-4 \% \mathrm{Fe}_{3} \mathrm{C}$} & \multirow{3}{*}{0.82} & 0.2 & 0.1321 & 3.0028 \\
\hline & & 0.4 & 0.1444 & 2.6134 \\
\hline & & 0.6 & 0.1569 & 2.4027 \\
\hline & \multirow{3}{*}{0.86} & 0.2 & 0.1264 & 3.3642 \\
\hline & & 0.4 & 0.0901 & 4.5001 \\
\hline & & 0.6 & 0.1769 & 2.7961 \\
\hline \multirow{6}{*}{$\mathrm{Al}-4 \% \mathrm{Mo}_{2} \mathrm{C}$} & \multirow{3}{*}{0.82} & 0.2 & 0.2938 & 2.5641 \\
\hline & & 0.4 & 0.1789 & 2.6111 \\
\hline & & 0.6 & 0.2161 & 2.4735 \\
\hline & \multirow{3}{*}{0.86} & 0.2 & 0.1260 & 3.5085 \\
\hline & & 0.4 & 0.1664 & 2.9745 \\
\hline & & 0.6 & 0.1706 & 2.8182 \\
\hline
\end{tabular}

TABLE 4: Approximation equation and the respective constants.

\begin{tabular}{lccc}
\hline Composition & & Constants & \multicolumn{2}{c}{ Approximation equation } \\
\hline $\mathrm{Al}-4 \% \mathrm{TiC}$ & 1.640 & $C_{2}$ & $\varepsilon_{\mathrm{eff}}^{f}=1.2580 /\left(4.920+\beta^{f}\right)$ \\
$\mathrm{Al}-4 \% \mathrm{WC}$ & -0.0483 & -1.9427 & $\varepsilon_{\mathrm{eff}}^{f}=0.2815 /\left(-0.1449+\beta^{f}\right)$ \\
$\mathrm{Al}-4 \% \mathrm{Fe}_{3} \mathrm{C}$ & 0.0296 & 4.7573 & $\varepsilon_{\mathrm{eff}}^{f}=0.4224 /\left(0.0888+\beta^{f}\right)$ \\
$\mathrm{Al}-4 \% \mathrm{Mo}_{2} \mathrm{C}$ & -0.4174 & -0.2254 & $\varepsilon_{\mathrm{eff}}^{f}=0.2822 /\left(-1.2522+\beta^{f}\right)$ \\
\hline
\end{tabular}

points and the approximation to workability limit for all the compositions are in good agreement and are applicable when fracture occurs at free surface for powder metallurgy materials.

The workability limit plot depicts that effective strain at fracture is a function of formability stress index at fracture $\left(\varepsilon_{\text {eff }}^{f}=f\left(\beta^{f}\right)\right)$. The general characteristics of the plot in Figures 1-4 are similar as $\varepsilon_{\text {eff }}^{f}$ decreases with the increasing $\beta^{f}$. The slope of the curve is found to be highest in $\mathrm{Mo}_{2} \mathrm{C}$ composite and lowest in $\mathrm{TiC}$ composite depicted from Figures 1-4. These plots are important for industrial applications as safe zone and unsafe zone can be used from these plots during the forming process.

The workability limit of the $\mathrm{TiC}$ reinforced preforms was found to be higher followed by $\mathrm{Fe}_{3} \mathrm{C}$ and $\mathrm{Mo}_{2} \mathrm{C}$ composites. WC reinforced preforms exhibited lowest workability limit for any specified effective strain. The material compositions are designed by weight fraction and $\mathrm{TiC}$ particulate being the smallest density followed by $\mathrm{Fe}_{3} \mathrm{C}, \mathrm{Mo}_{2} \mathrm{C}$, and $\mathrm{WC}$ as seen in Table 2. This means the amount of smaller and fine voids existing in $\mathrm{Al}-4 \% \mathrm{TiC}$ compact is more compared to other materials tested. The actual closing of voids is more in $\mathrm{TiC}$ compacts during hot upsetting increasing the density which intend gives high workability limit for $\mathrm{TiC}$ compacts.

\section{Conclusions}

The theoretical correlation between effective strain and formability stress factor at fracture was acquired, which was used for constructing workability limit plot for $\mathrm{Al}-4 \% \mathrm{TiC}, \mathrm{Al}-$ $4 \% \mathrm{WC}, \mathrm{Al}-4 \% \mathrm{Fe}_{3} \mathrm{C}$, and $\mathrm{Al}-4 \% \mathrm{Mo}_{2} \mathrm{C}$. It is established that hyperbolic curve acquired from Oyane's fracture criterion for the theoretical relationship showed good agreement with the 
experimental results; hence these workability limit plots can be used in forming processes.

\section{Conflict of Interests}

The authors declare that there is no conflict of interests regarding the publication of this paper.

\section{References}

[1] G. Poshal and P. Ganesan, "Neural network approach for the selection of processing parameters of aluminium-iron composite preforms during cold upsetting," Journal of Engineering Manufacture, vol. 224, no. 3, pp. 459-472, 2010.

[2] G. Abouelmagd, "Hot deformation and wear resistance of $\mathrm{P} / \mathrm{M}$ aluminium metal matrix composites," Journal of Materials Processing Technology, vol. 155-156, no. 1-3, pp. 1395-1401, 2004.

[3] A. Rosochowski, L. Beltrando, and S. Navarro, "Modelling of density and dimensional changes in re-pressing/sizing of sintered components," Journal of Materials Processing Technology, vol. 80-81, pp. 188-194, 1998.

[4] J. Mascarenhas, "Powder metallurgy: a major partner of the sustainable development," Materials Science Forum, vol. 455456, pp. 857-860, 2004.

[5] Y. Sahin, "Preparation and some properties of SiC particle reinforced aluminium alloy composites," Materials and Design, vol. 24, no. 8, pp. 671-679, 2003.

[6] Y. Sahin, "The effect of sliding speed and microstructure on the dry wear properties of metal-matrix composites," Wear, vol. 214, no. 1, pp. 98-106, 1998.

[7] R. Derakhshandeh. H and A. Jenabali Jahromi, "An investigation on the capability of equal channel angular pressing for consolidation of aluminum and aluminum composite powder," Materials and Design, vol. 32, no. 6, pp. 3377-3388, 2011.

[8] S. M. Zebarjad and S. A. Sajjadi, "Dependency of physical and mechanical properties of mechanical alloyed $\mathrm{Al}^{-\mathrm{Al}_{2} \mathrm{O}_{3}}$ composite on milling time," Materials and Design, vol. 28, no. 7, pp. 2113-2120, 2007.

[9] J. B. Fogagnolo, F. Velasco, M. H. Robert, and J. M. Torralba, "Effect of mechanical alloying on the morphology, microstructure and properties of aluminium matrix composite powders," Materials Science and Engineering A, vol. 342, no. 1-2, pp. 131143, 2003.

[10] B. Prabhu, C. Suryanarayana, L. An, and R. Vaidyanathan, "Synthesis and characterization of high volume fraction Al$\mathrm{Al}_{2} \mathrm{O}_{3}$ nanocomposite powders by high-energy milling," Materials Science and Engineering A, vol. 425, no. 1-2, pp. 192-200, 2006.

[11] S. Sheibani and M. F. Najafabadi, "In situ fabrication of Al-TiC Metal Matrix Composites by reactive slag process," Materials and Design, vol. 28, no. 8, pp. 2373-2378, 2007.

[12] L. Zhong, Y. Xu, M. Hojamberdiev, J. Wang, and J. Wang, "In situ fabrication of titanium carbide particulates-reinforced iron matrix composites," Materials and Design, vol. 32, no. 7, pp. 3790-3795, 2011.

[13] C. Y. Liu, Q. Wang, Y. Z. Jia et al., "Evaluation of mechanical properties of 1060-Al reinforced with WC particles via warm accumulative roll bonding process," Materials \& Design, vol. 43, pp. 367-372, 2013.
[14] R. Narayanasamy, T. Ramesh, and K. S. Pandey, "Some aspects on workability of aluminium-iron powder metallurgy composite during cold upsetting," Materials Science and Engineering A, vol. 391, no. 1-2, pp. 418-426, 2005.

[15] M. Abdel-Rahman and M. N. El-Sheikh, "Workability in forging of powder metallurgy compacts," Journal of Materials Processing Tech., vol. 54, no. 1-4, pp. 97-102, 1995.

[16] D. Vilotić, M. Plančk, S. Grbić, S. Alexandrov, and N. Chikanova, "An approach to determining the workability diagram based on upsetting tests," Fatigue and Fracture of Engineering Materials and Structures, vol. 26, no. 4, pp. 305-310, 2003.

[17] D. Vilotić, M. Plančak, D. Čupković, S. Alexandrov, and N. Alexandrova, "Free surface fracture in three upsetting tests," Experimental Mechanics, vol. 46, no. 1, pp. 115-120, 2006.

[18] A. El-Domiaty, "Cold workability limits for carbon and alloy steels," Journal of Materials Engineering and Performance, vol. 8, no. 2, pp. 171-183, 1999.

[19] S. Narayan and A. Rajeshkannan, "Densification behaviour in forming of sintered iron $-0.35 \%$ carbon powder metallurgy preform during cold upsetting," Materials and Design, vol. 32, no. 2, pp. 1006-1013, 2011.

[20] D. Shanmugasundaram and R. Chandramouli, "Tensile and impact behaviour of sinter-forged $\mathrm{Cr}, \mathrm{Ni}$ and Mo alloyed powder metallurgy steels," Materials and Design, vol. 30, no. 9, pp. 3444-3449, 2009.

[21] L. Hua, X. Qin, H. Mao, and Y. Zhao, "Plastic deformation and yield criterion for compressible sintered powder materials," Journal of Materials Processing Technology, vol. 180, no. 1-3, pp. $174-178,2006$.

[22] X. Q. Zhang, Y. H. Peng, M. Q. Li, S. C. Wu, and X. Y. Ruan, "Study of Workability Limits of Porous Materials under Different Upsetting Conditions by Compressible Rigid Plastic Finite Element Method," Journal of Materials Engineering and Performance, vol. 9, no. 2, pp. 164-169, 2000.

[23] Y. Bao, "Dependence of ductile crack formation in tensile tests on stress triaxiality, stress and strain ratios," Engineering Fracture Mechanics, vol. 72, no. 4, pp. 505-522, 2005.

[24] Y. Bao and T. Wierzbicki, "On fracture locus in the equivalent strain and stress triaxiality space," International Journal of Mechanical Sciences, vol. 46, no. 1, pp. 81-98, 2004.

[25] H. A. Kuhn and C. L. Downey, "How flow and fracture affect design of preforms for powder forging," International Journal of Powder Metallurgy \& Powder Technology, vol. 10, no. 1, pp. 5966, 1974.

[26] B. Hwang and S. Kobayashi, "Deformation characterization of powdered metals in compaction," International Journal of Machine Tools and Manufacture, vol. 30, no. 2, pp. 309-323, 1990.

[27] M. A. Shabara, A. A. El-Domiaty, and A. Kandil, "Validity assessment of ductile fracture criteria in cold forming," Journal of Materials Engineering and Performance, vol. 5, no. 4, pp. 478488, 1996.

[28] X. ZHANG, W. ZENG, Y. SHU et al., "Fracture criterion for predicting surface cracking of Ti40 alloy in hot forming processes," Transactions of Nonferrous Metals Society of China, vol. 19, no. 2, pp. 267-271, 2009.

[29] R. Narayanasamy, V. Anandakrishnan, and K. S. Pandey, "Effect of carbon content on workability of powder metallurgy steels," Materials Science and Engineering A, vol. 494, no. 1-2, pp. 337342, 2008. 
[30] X. P. Qin and L. Hua, "Deformation and strengthening of sintered ferrous material," Journal of Materials Processing Technology, vol. 187-188, pp. 694-697, 2007.

[31] H. N. Han, K. H. Oh, and D. N. Lee, "Analysis of forging limit for sintered porous metals," Scripta Metallurgica et Materiala, vol. 32, no. 12, pp. 1937-1944, 1995.

[32] R. W. Lewis and A. R. Khoei, "A plasticity model for metal powder forming processes," International Journal of Plasticity, vol. 17, no. 12, pp. 1659-1692, 2001.

[33] S. Narayan and A. Rajeshkannan, "Workability studies in forming of sintered iron $-0.35 \%$ carbon powder metallurgy preform during cold upsetting," Journal of Iron and Steel Research International, vol. 18, no. 12, pp. 71-78, 2011.

[34] S. Narayan and A. Rajeshkannan, "Influence of carbon content on workability behavior in the formation of sintered plain carbon steel preforms," International Journal of Advanced Manufacturing Technology, vol. 64, no. 1-4, pp. 105-111, 2013.

[35] R. Narayanasamy, R. Ponalagusamy, and K. R. Subramanian, "Generalized yield criteria of porous sintered powder metallurgy metals," Journal of Materials Processing Technology, vol. 110, no. 2, pp. 182-185, 2001.

[36] R. Narayanasamy, V. Anandakrishnan, and K. S. Pandey, "Effect of geometric work-hardening and matrix work-hardening on workability and densification of aluminium-3.5\% alumina composite during cold upsetting," Materials and Design, vol. 29, no. 8, pp. 1582-1599, 2008.

[37] S. Shima and M. Oyane, "Plasticity theory for porous metals," International Journal of Mechanical Sciences, vol. 18, no. 6, pp. 285-291, 1976.

[38] S. M. Doraivelu, H. L. Gegel, J. S. Gunasekera, J. C. Malas, J. T. Morgan, and J. F. Thomas Jr., "A new yield function for compressible P M materials," International Journal of Mechanical Sciences, vol. 26, no. 9-10, pp. 527-535, 1984. 

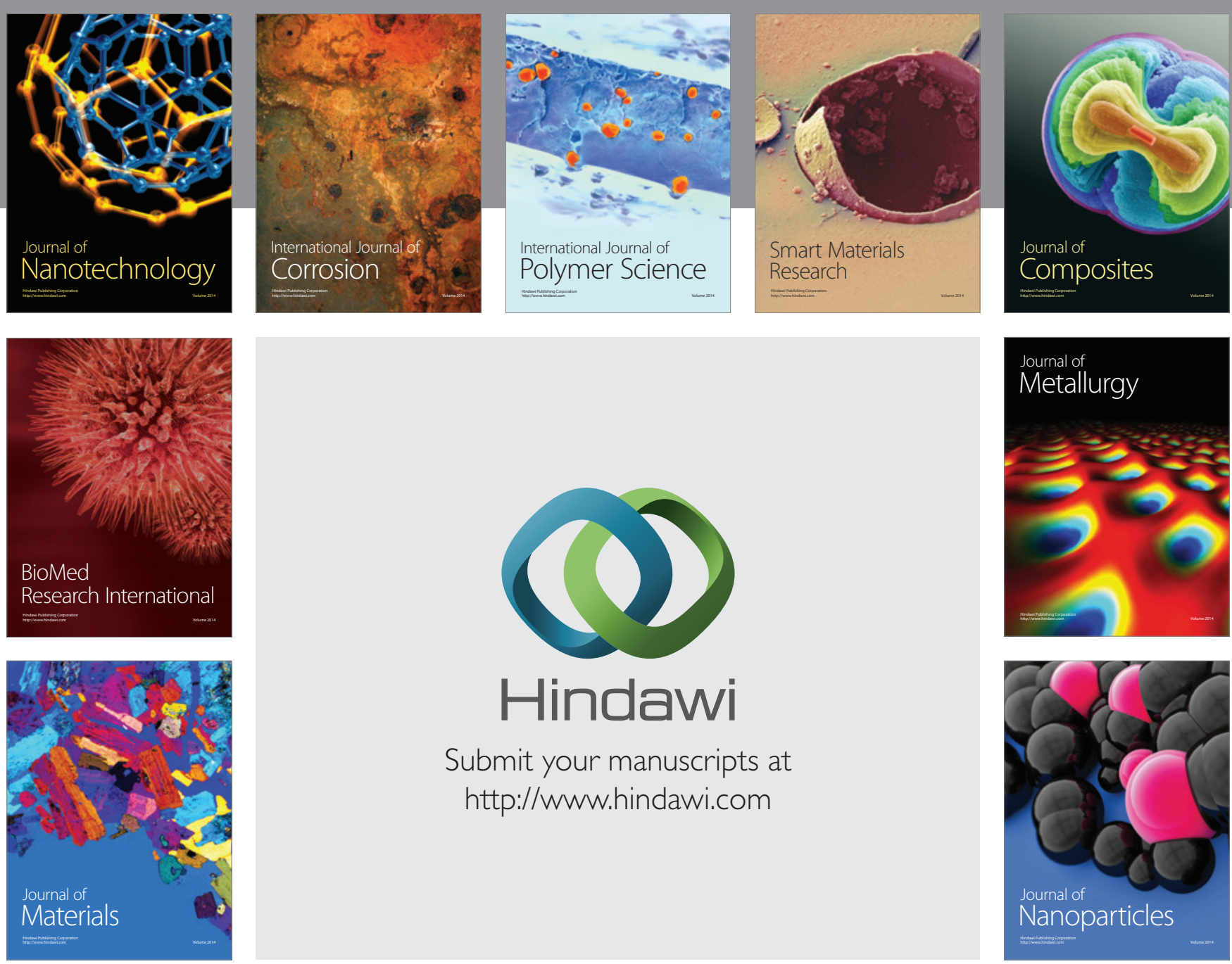

Submit your manuscripts at http://www.hindawi.com
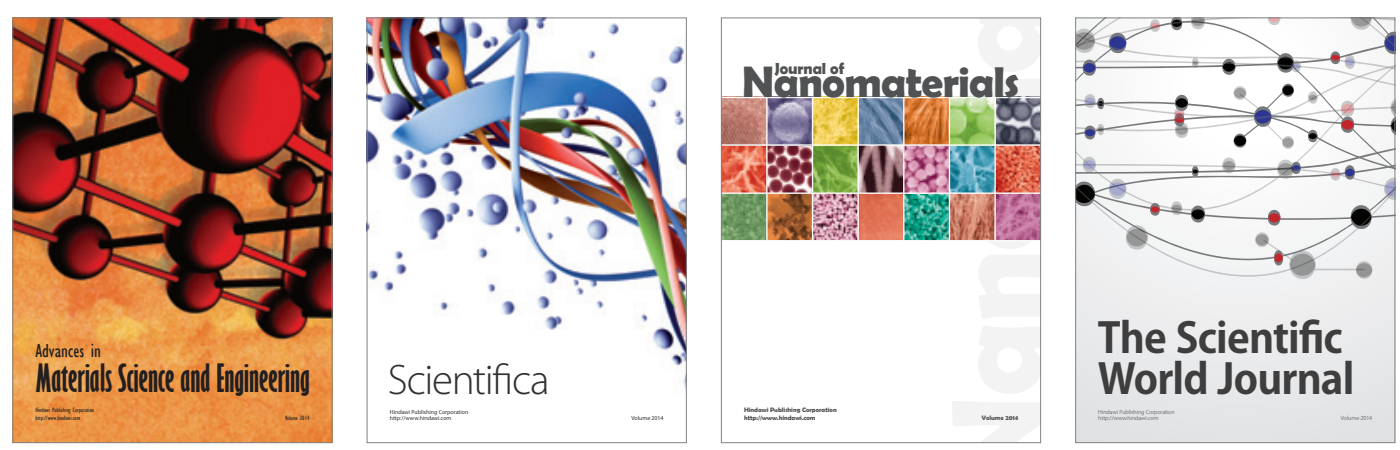

\section{The Scientific World Journal}
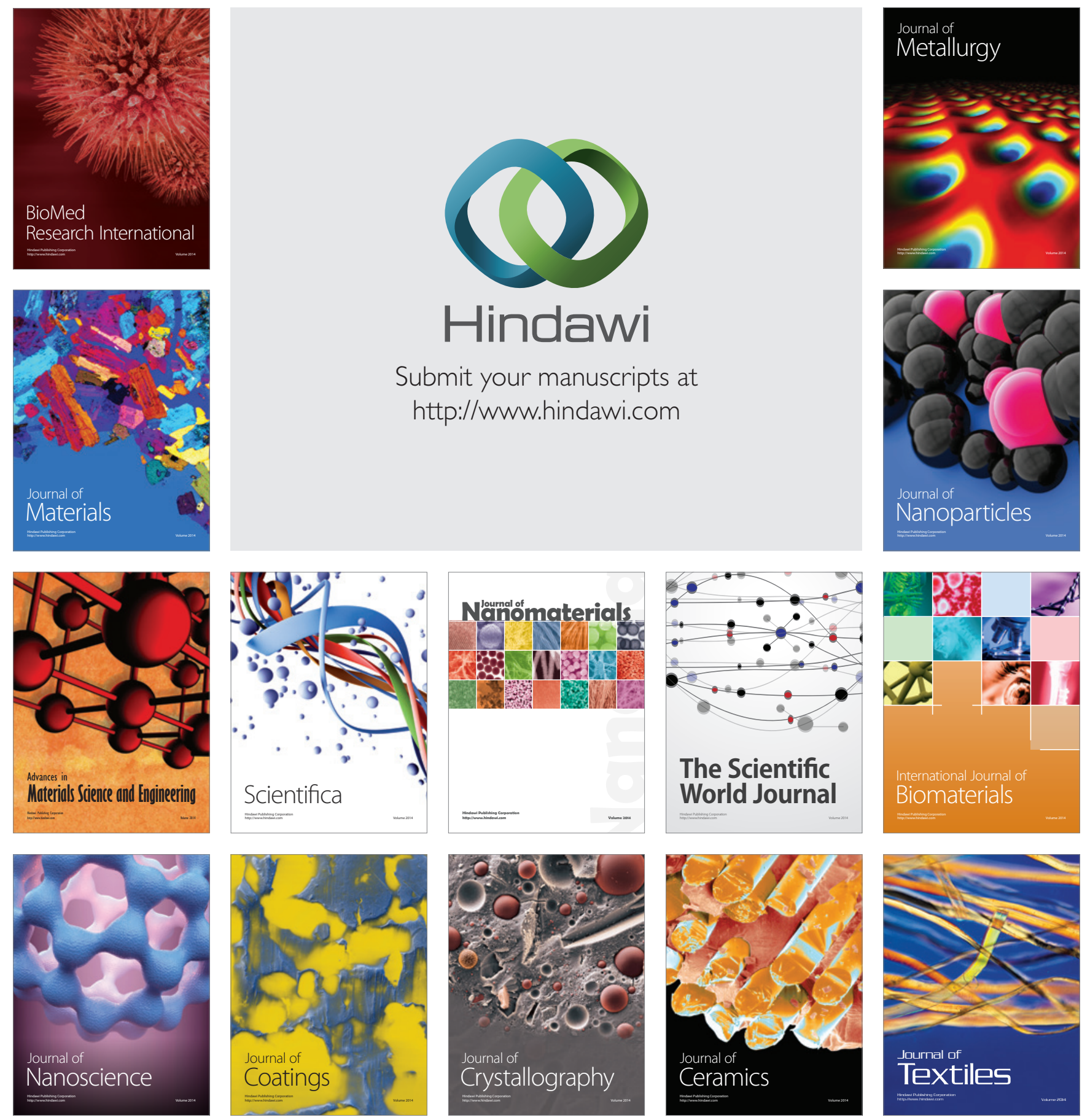